\title{
AN EXPERIMENT IN TEACHING OPERATIONS MANAGEMENT TO SIXTH GRADERS USING SIMULATION
}

\author{
Theresa M. Roeder \\ Department of Decision Sciences \\ San Francisco State University \\ San Francisco, CA 94132, USA
}

\author{
Karen N. Roeder \\ Bamberg Elementary School \\ Department of Defense Dependents Schools \\ Bamberg, Bavaria 96047, GERMANY
}

\begin{abstract}
Over the past decade, efforts have been made to incorporate Operations Management and Operations Research into pre-college school curricula. Not only does this approach introduce students earlier to a relatively unknown field, but it also provides a different side of mathematics, showing that math can be very real-world specific, practical, and relevant. In this paper, we describe a semester-long research project working with a group of 14 sixth grade students at a US military base in Germany. At the end of the semester, students presented the results of a discrete event simulation study to their parents and peers. We feel the project was very successful, and would encourage others to try similar projects.
\end{abstract}

\section{INTRODUCTION}

Operations Research (O.R.) and Operations Management (O.M.) are relatively new fields. Perhaps partly because of this, they are faced with the difficult problem of very few people recognizing their existence or value. By the time most students are exposed to O.R. in college, if they are at all, it may be "too late" to capture their attention: many have already concluded that math is "too hard," or have turned to other technical fields such as engineering. This is a pity, as O.R./O.M. are more than simply another form of mathematical analysis: they analyze and solve real-world problems in a structured way. Because their science-based methods can be applied to concrete business and real-life situations, they provide a mathematical foundation for cultivating and reinforcing intuition in decision making situations that can be readily understood at any age. As Richard Larson said in his keynote speech at the INFORMS 2009 conference, O.R. seems the perfect gateway to introducing students to math (Larson 2009).

Because of this, O.M. - especially animated simulation models - presents an opportunity to introduce students to a different side of math than they might be used to seeing. Rather than trying to interest students in abstract concepts such as algebra, showing how mathematics plays a large role in everyday life can be invigorating. If students find an early application for and love of mathematics, they may be more inclined to pursue it further as they grow older. This is especially of concern for women and minorities; both groups are underrepresented in technical fields, in part because of societal pressures and gender role preconceptions. (See Simard (2009) for a detailed survey of recent statistics and literature about this phenomenon.)

In this paper, we describe an experimental study of math enrichment, performed with a group of sixth graders at Bamberg Elementary School (BES), a U.S. military school in Germany, in cooperation with the Department of Decision Sciences at the San Francisco State University (SFSU). Over the course of a semester, students were introduced to the ideas of variability and probability, and developed discrete event simulations to evaluate system performances. At the end of the semester, students presented their work to their peers, parents, and administrators. The purpose of the study was to determine whether elementary 
school students had the cognitive skills to understand probabilistic concepts, and to analytically evaluate real-world situations. The conclusions from our study are optimistic.

Section 2 gives background information on ongoing efforts to teach O.R. at the pre-college level, as well as background on the overseas school system. Section 3 describes the math enrichment program in detail. Concluding remarks are given in Section 4.

\section{BACKGROUND}

\subsection{Teaching O.R. and Applied Mathematics at the Pre-College Level}

In the last five years, significant effort has been made to introduce O.R. into high school curricula to make math more meaningful to students. Edwards and Chelst (2004) outline the foundation of and structure for the High School Operations Research Outreach (HSOR) program, a program that trains high school teachers and provides them with course modules that use O.R. problems to illustrate the hands-on nature of mathematics. The program has been in existence for over 10 years. Project MINDSET, an NSFfunded multi-year project, is developing a full O.R. course for high schools, along with a training and support program for the teachers (Chelst et al. 2008; Chelst et al. 2010). Chelst and Edwards (2012) illustrate how the course can be used in the context of the new common core being adopted by states across the country (Common Core State Standards Initiative 2013). This paper provides anecdotal evidence showing that O.R. can effectively be used even with sixth graders, not just high school students. Simulation itself is also increasing in popularity as a tool to teach O.R. concepts. To this end, van der Zee, Holkenburg, and Robinson (2012) introduce a conceptual modeling approach for developing "serious gaming" applications.

More broadly speaking, there are significant efforts to increase the popularity of math and science with younger students. The Science from Scientists (formerly Whizkids) Foundation is a donation-driven non-profit group that promotes math and science education by providing practical assistance to students, teachers, and administrators in science projects and activities promoting science (Science from Scientists 2013). BLOSSOMS is an international collaboration to provide open-source video modules to high school math and science teachers around the world (Blended Learning Open Source Science or Math Studies 2013).

\subsection{Department of Defense Dependent Schools}

Since the end of World War II, the US Department of Defense has operated an overseas school system to serve the children of those affiliated with the Armed Services, the Department of Defense Dependent Schools (DoDDS). The school system is equivalent to American school systems in the United States, and is funded by the Federal Government. Teachers are U.S. certified, and a full range of services is available to all students, those with special needs as well as the talented and gifted.

Schools serve a diverse population of students, from the children of well-educated university graduates to students of immigrants with ESL needs. Unlike stateside schools where different school districts may have different financial means and different student demographics, DoDDS schools are uniformly funded, with a student population unique in that every family has at least one working parent.

In DoDDS, sixth grade may be part of the elementary school system or incorporated into a middle school. In an elementary school, students generally spend the majority of their day in their homeroom, with their classroom teacher responsible for teaching most or all subjects. Because of this, the students' schedule is relatively flexible for other activities during the day.

\section{THE MATHEMATICS ENRICHMENT PROGRAM}

The math enrichment program was run during the Spring 2008 semester. It was motivated by student response to previous years' presentations on the importance and applications of math. For this program, all sixth graders were introduced to the ideas of applied math by a presentation from the first author, an assis- 


\section{Roeder and Roeder}

tant professor, in January. She spent the remaining week working with the self-selected group of students during their regular math period. After her return to California, all parties communicated through the SFSU online course management system (CMS). The first author returned to Germany in May, 2008, for another week of one-on-one work with students. At the end of the week, students presented their findings to their parents, peers, and administrators.

\subsection{The Students}

Students self-selected into this project. Originally, we had planned to choose high-achieving students to participate, but decided to allow students to make the decision themselves. Of the 60 sixth graders, 16 elected to take part, seven girls and nine boys. (Two boys later dropped out.) Students and parents were told that this was a math enrichment program, and was in addition to, not a replacement for, regular math lessons. This meant that students would have to do work outside the regular classroom hours, either during recess or after school in the classroom, or at home.

The students included high-achievers, as expected. However, there were also several special needs students with learning disabilities and/or behavioral problems. All the special needs students completed the program successfully.

\subsection{Simulation Package}

The simulation software used for the course was Arena 7.0 by Rockwell Automation. It is a process interaction-based discrete event package. The educational version of Arena is available free of charge to educators. It was installed on two computers in one of the sixth grade classrooms.

The advantage of a process interaction-based package like Arena is that the simulation is structured largely like a flow chart of the process(es) jobs go through. For beginners, this is an extremely intuitive approach to simulation modeling.

\subsection{The Lessons}

Introducing elementary students to the concepts necessary for building discrete-event simulation models was challenging. Students had to learn the concepts of variability, probability, and probability distributions - without having the math background that is normally assumed at the high school or college level.

Figure 1 shows the math standards for the Department of Defense Education Activity (DoDEA) (Department of Defense Education Activity Math Standards, Grade 6, 2009). The lessons/worksheets covered most of the Data Analysis and Probability goals, especially goals 6.M5b, c, and f. Goal 6.M5g was taken significantly surpassed by analyzing the situations dynamically through simulations, rather than merely statically through lists. The Algebra goals were addressed indirectly at best.

The first three worksheets were done in person. The remaining six worksheets were completed over the course of the semester, using the CMS.

\subsubsection{Worksheet 1: Considering a Real-Life Scenario}

For the first worksheet, students were asked to consider a scenario from their daily lives. They were asked to briefly describe the scenario, then to explain the advantages and disadvantages of the "current setup." They were asked to think about how the current setup could be improved, and how they could "tell" that an improvement had taken place.

In class, we discussed the on-base movie theater. We sketched the layout of the theater lobby on the board, and discussed the disadvantages of the current way in which concessions were sold. Students commented that the line for the concessions is very long, and that part of the problem was that people did not know what they wished to order until they had reached the front of line. They suggested posting the menu on posters, so people could think about what they wanted while they were waiting in line. They also 


\section{Roeder and Roeder}

suggested posting signs reminding customers to be ready to order when they got to the head of the line. Students also explored the idea of "cross-training" the cashiers to allow for greater flexibility (e.g., if one focused on ringing up customers the other could put together the order).

Students recommended several measures for the system. They quickly thought of ideas like looking at the length of the line, or how long customers wait in line. The discussion expanded to include thoughts on how efficiently the cashiers were being used, and whether a better system might be able to even eliminate one of the two as a cost-savings measure.

\section{M2 Algebra}

- 6.M2a Recognize and generate equivalent forms of algebraic expressions.

- 6.M2b Explain how the commutative, associative and distributive properties generate equivalent forms;

- 6.M2c Solve simple linear equations and inequalities;

- 6.M2d Use symbolic algebra to represent situations, i.e., relationships found in geometry;

- 6.M2e Evaluate simple expressions by replacing variables with given values, and use formulas in problem-solving situations;

- 6.M2f Create and interpret tables and graphs to draw conclusions and make predictions;

- 6.M2g Create and compare representations that display constant and varying rates of change.

\section{M5 Data Analysis and Probability}

- $\quad$ 6.M5a Read and use graphical representations to make predictions and/or draw conclusions;

- 6.M5b Formulate questions, design a study, and evaluate the data to reach a conclusion about characteristics shared by two populations or different characteristics that exist within a population;

- $\quad 6 . M 5 c$ Identify the measures of central tendency and spread of a data set to describe what it indicates about the data set;

- 6.M5d Explain the effects of scale and/or interval changes in graphs that lead to misunderstandings;

- 6.M5e Select, construct, interpret, and justify the appropriate graphical representation of data;

- 6.M5f Use 0,1 , and ratios between 0 and 1 to represent the probability of outcomes for an event;

- 6.M5g Describe and model all possible outcomes of simple events using tree diagrams, organized lists, etc.;

- 6.M5h Explain why the sum of the probabilities of all possible outcomes of a particular event is one.

Figure 1: Department of Defense Education Activity Sixth Grade Math Standards

\subsubsection{Worksheet 2: Uncertainty, Variability, and Probability}

Worksheet 2 was more abstract, and therefore more difficult. We discussed what uncertainty was, and why it causes difficulties. Similarly, we discussed variability and its complications. The example that resonated most with them was the variability in school bus arrival times, and the ensuing complications. We talked about the concept of probability, and then discussed what histograms were and why they were useful. The students were told to go home and collect data - the numbers of pens and pencils in each room of the house - and construct histograms. In class we compared each person's histogram. We then constructed a histogram of the lengths of time students had been stationed in Bamberg (the distribution was rightskewed). 


\subsubsection{Worksheet 3: Probability Distributions}

The discussion of histograms in Worksheet 2 was the lead-in to a more in-depth discussion of probability distributions. Rather than focusing on technical definitions, we took the idea of probability ("how likely something is to happen") and looked at possible shapes of distributions. Specifically, we considered four different ones: uniform, bathtub, normal, and exponential. In each case, we discussed what the shape implied, and brainstormed different things that might follow that distribution. By and large, students did well - though there was some discussion of the bathtub-shaped distribution representing roller coasters.

\subsubsection{Worksheet 4: Introducing the Arena Simulation Package}

Worksheet 4 was the first of a series of worksheets that was completed remotely. Unfortunately, this was the point when students were starting to work with the software. As a consequence, the worksheets were step-by-step tutorials on how to accomplish things in Arena.

In Worksheet 4, students went through the process of opening and running an existing simulation model in Arena. The model was the sample emergency room simulation that is delivered with Arena. Students had previously seen the model during the presentation to all sixth graders.

\subsubsection{Worksheet 5: Experimenting with an Existing Simulation}

After a simulation model is built and verified, the next step is typically to do sensitivity or what-if analysis. In Worksheet 5, students experimented with changing the number of nurses working at the emergency room's triage station in order to alleviate the high utilization there.

Once the number of nurses at the triage station was set to a reasonable number, students noticed that other resources became more highly utilized. They correctly identified the problem that with more patients being able to "get through" the triage now, more work was being created in other parts of the emergency room (shifting bottleneck).

\subsubsection{Worksheet 6: Processes}

In order to prepare students to build their own simulation models, Worksheet 6 took a step back and looked at the idea of a process. Students had been introduced to the idea of explicit instructions for completing a process during the presentation in January. In it, the first author asked them to give her instructions on how to put on her jacket, which was hanging (buttoned up) on a coat hanger. In that exercise, students quickly learned the importance of precision - there are many ways to put one's arm (which one?) "in the jacket!"

For their assignment in Worksheet 6, students were asked to describe the process they go through every morning when getting ready to go to school. They identified the steps, and where in the process there might be differences from day to day. They discussed areas where they could be more efficient and, again (looking back at Worksheet 1), how they could tell whether they had improved the process.

\subsubsection{Worksheets 7 and 8: Building a Simulation in Arena}

In Worksheets 7 and 8, students built a basic simulation model of the cashier process at the Post Exchange (PX). The simulation consisted of a CREATE, a PROCESS, and a DISPOSE block in Arena. Students were asked to choose and justify their own interarrival distribution. They learned how to specify output statistics of interest, as well as add things like a simulation clock to the window.

After running the simulation, students looked at the output statistics generated by Arena, and interpreted them. Students quickly understood the concept of resource utilization. They also were able to interpret average queue size and waiting times, as well as the minimum and maximum values. 


\section{Roeder and Roeder}

\subsubsection{Worksheet 9: Developing a New Simulation Model}

In Worksheet 9, each student team was finally asked to develop its own simulation model. They were instructed to decide on a scenario they wanted to simulate, and repeat the exercise we went through for Worksheet 1. Each team then had to draw a flow chart of the resulting process. Figure 2 shows the flow chart submitted by the girls' team, who was simulating the on-base movie theater.

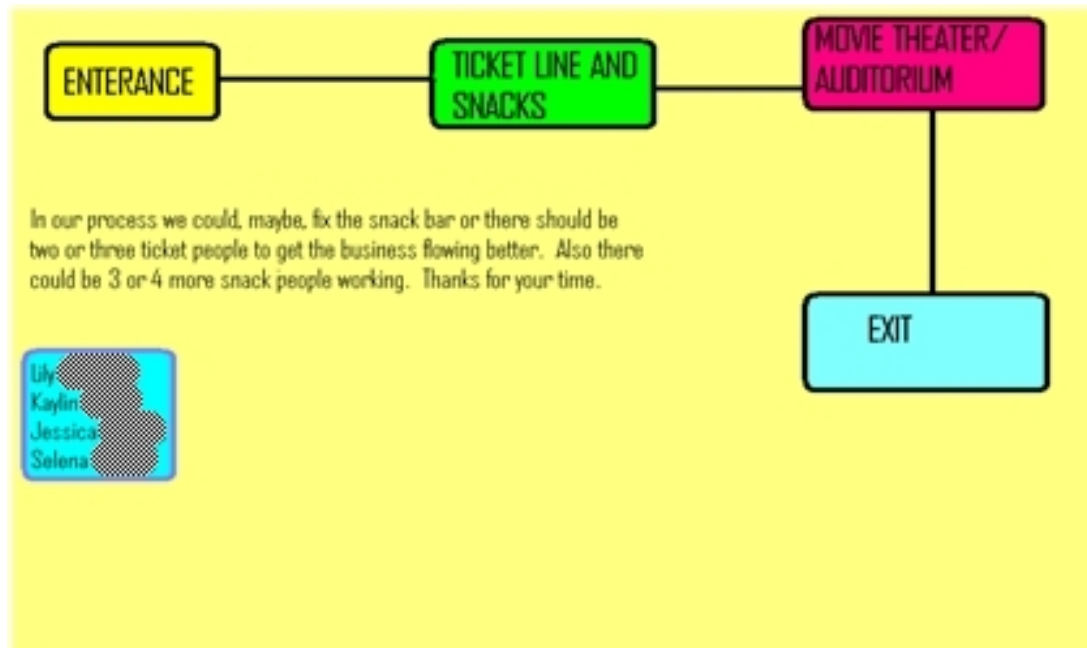

Figure 2: Movie theater flow chart submitted by students as a first step towards developing their simulation models

After the teams had completed their flow charts, the first author returned, and was able to assist in building the actual simulation models. At the same time, students were developing their PowerPoint slides for the presentations to their classmates.

\subsection{Presentations}

Students spent the last week of classes working on their simulation models, but also on their PowerPoint presentations. We had a discussion of good structures for presentations (outlines etc.), and also of important points to remember while presenting. They then repeatedly practiced in front of each other to become more comfortable speaking in front of an audience.

Over the course of the week, the students created very sophisticated presentations. At one point, the boys' group discovered animation and sound effect features, which took the girls' group completely by surprise. (They then spent several hours "prettying" up their presentation.)

Students presented their projects to the other sixth graders and a class of fifth graders, school administrators, a counselor, and their parents. While they were extremely nervous, they did an admirable job, even speaking without looking at their notes.

In their presentations, they took the audience through the steps we had gone through, defining variability and probability, and explaining the purpose of simulation models in general, and their group's simulation model, in particular. They did live demos of their models, and then explained the results of their what-if analysis. They were able to field questions from the audience, including explaining utilization and histograms.

The boys' project was about McDonald's. They looked at how many cashiers should be working, given the assumed arrival distribution. (The conclusion was two cashiers were acceptable.) 


\section{Roeder and Roeder}

The girls' project was about the movie theater on base. They had two parameters, the number of cashiers (to sell tickets) and the number of people working at the concession stand. (One cashier and four concession workers.)

\subsection{Administrative Structure}

A fair amount of administrative support was required to complete the project. The administration at the elementary school was fully engaged, and provided authorization for the first author to get on base without needing an escort. In addition, they enabled her to meet with students for this project.

The university IT department set up an online course so the project could continue when the first author returned to California. Students set up email accounts through the elementary school, and were then given accounts for the university course management system (CMS). The online course was used to share files and for group communications.

The project was in addition to, not a substitute for, regular math classes. While the first author was working with students in person, students spent their math period working on the project. They did their regular math work when they had time during the rest of the day, either when they had completed work for other subjects, or during recess. Students were also given additional homework to do for the enrichment program.

In order for students to complete their simulation projects, software had to be installed on computers at the elementary school. Rockwell Software and the school administration agreed to allow Arena 7.0 to be installed on the two computers in the second author's classroom.

\section{FUTURE IMPLEMENTATIONS}

This pilot project was possible because of the close relationship between the authors. However, since the results seem positive and materials have been developed, we see no reason why similar enrichment programs could not be possible in the future, with different participants.

While having a university professor work with students is an advantage in that they are impressed and eager to participate, higher education need not be present in the program. Elementary or middle school teachers could easily be instructed in the concepts and operation of the software. Drag-and-drop packages such as Arena lend themselves well to this purpose because of their ease of use, but it is certainly possible to use other programs, depending on the sophistication of the students.

It is unclear whether this program could be done as part of the regular mathematics curriculum, rather than as an extra-curricular enrichment. In order to become a part of the general subject material, more significant changes would need to made, at the school if not district level. Perhaps it could be considered as a possibility for Project MINDSET (Chelst et al. 2010).

\section{CONCLUSIONS}

Overall, we are very pleased with the results of the project. The students were genuinely excited about working on it, and being able to build simulation models on their own, on topics of their own choosing. We also feel that they learned much about examining "everyday" situations more analytically - asking how they could be improved and measured. They became familiar with how important mathematics and analysis are in making informed decisions - and how important it is to continue studying mathematics. They were introduced to the field of Operations Research, and enjoyed what they learned of it.

On a broader level, the students worked independently and were able to learn from written, static instructions (as opposed to interactive instructions). They were willing to take on the extra work, and did (in some cases) significant work outside of school. We know they spent quite some time rehearsing their presentations.

For the presentations, students learned about structuring a presentation logically as well as making an actual presentation - facing the audience, speaking clearly and without notes, etc. In fact, they were better 


\section{Roeder and Roeder}

prepared and more at ease in presenting than many of the college junior and senior business students we have observed.

Finally, they also became more computer literate over the course of the project. By the end, they were readily able to email with attachments, use the CMS, manipulate the simulation model, and create presentations that were pleasing to the eye.

We feel that the project would benefit significantly if the instructors were both present throughout its duration. In this case, material could be introduced in more depth, and there would be more opportunities to engage students in discussions on a wider range of topics. We do not feel that the topics were too sophisticated or advanced for the students, and would not hesitate to repeat the experiment. It is heartening that the O.R. outreach can be done with students as young as 11 and 12 . It was also gratifying to have such a large number of girls participate in the project so excitedly. We hope to have inspired them to be lifelong enthusiasts for math in general and, with any luck, for O.R., in particular.

\section{ACKNOWLEDGMENTS}

This project would not have been possible without the support of Bamberg Elementary School administration and staff. In particular, we would like to thank Sandra Kuplinski and Cindy Templeton, as well as Laura Spencer. Thanks also to Parrish Worrell, Mary Acevedo, Eudelia Martinez, Christine Chang, and Lothar Roeder for their support. Robert Saltzman and Özgür Özlük were also helpful in encouraging the project.

\section{REFERENCES}

Department of Defense Education Activity Math Standards, Grade 6. 2009. last accesed October 4, 2009. http://www.dodea.edu/curriculum/docs/math/2009_stn_math_grd6.pdf.

Blended Learning Open Source Science or Math Studies. 2013a. last accesed May 20, 2013. http://blossoms.mit.edu/.

Common Core State Standards Initiative. 2013b. last accesed July 14, 2013. http://www.corestandards.org/.

Science from Scientists Foundation. 2013c. last accesed May 20, 2013. http://sciencefromscientists.org.

Chelst, K. R., and T. Edwards. 2012. Operations Research Aligned with the Common Core Revolution in K-12 Mathematics Education. OR/MS Today 39 (4).

Chelst, K. R., T. Edwards, R. Young, K. Keene, K. Norwood, and D. Pugalee. 2010. When Will I Ever Use This Stuff? OR/MS Today 37 (4).

Chelst, K. R., T. G. Edwards, R. Young, K. Keene, and D. Royster. 2008. Can You Imagine ... 500,000 Prep Proponents of O.R.? OR/MS Today, August 35 (4).

Edwards, T. G., and K. R. Chelst. 2004. "The HSOR Project: Insinuating OR into High School Mathematics Classrooms." INFORMS Transactions on Education 4 (3).

Larson, R. 2009. Worldwide Reach into High School Math and Science Classes. INFORMS 2009 Keynote, at San Diego, CA.

Simard, C. 2009. Obstacles and Solutions for Underrepresented Minorities in Technology. http://anitaborg.org/files/obstacles-and-solutions-for-underrepresented-minorities-in-technology.pdf.

van der Zee, D.-J., B. Holkenburg, and S. Robinson. 2012. "Conceptual Modeling for Simulation-Based Serious Gaming." Decision Support Systems 54 (1):33-45. 
Roeder and Roeder

\section{AUTHOR BIOGRAPHIES}

THERESA ROEDER is an Associate Professor of Decision Sciences in the College of Business at San Francisco State University. She teaches courses in Operations Management, Computer Simulation, Applied Management Science, and, Communications for Business Analytics. She earned her Ph.D. in Industrial Engineering and Operations Research from the University of California, Berkeley, and B.S. and M.S. degrees in Management Science from Case Western Reserve University. Her research interests are in simulation methodology, O.R. education, and health care. Her email address is tmroeder@sfsu.edu.

KAREN ROEDER is a retired teacher who served with the Department of Defense Dependents' Schools for thirty-eight years. During that time, she had self-contained classes in grades $1-4$, and in grade 6, both self-contained and departmentalized classes, teaching language arts and social studies. She was also a Reading Specialist and consultant for teachers of grades $\mathrm{K}-6$, taught remedial reading to students in grades 3-6, conducted in-services and workshops for teachers in reading, and held workshops and tutorials for parents in beginning-reading activities and pre-algebra concepts. Her degrees are a B.S. in education from the University of Wisconsin, Madison, and an M.ED. from the University of Hawaii, Manoa. Her email address is karennroeder@gmail.com. 